\title{
The miRNAome of the postpartum dairy cow liver in negative energy balance
}

Attia Fatima ${ }^{1,2}$, David J Lynn³ ${ }^{3}$ Padraic O'Boyle ${ }^{2}$, Cathal Seoighe ${ }^{2}$ and Dermot Morris ${ }^{1 *}$

\begin{abstract}
Background: Negative energy balance (NEB) is an altered metabolic state in high yielding cows that occurs during the first few weeks postpartum when energy demands for lactation and maintenance exceed the energy supply from dietary intake. NEB can, in turn, lead to metabolic disorders and to reduced fertility. Alterations in the expression of more than 700 hepatic genes have previously been reported in a study of NEB in postpartum dairy cows. miRNAs (microRNA) are known to mediate many alterations in gene expression post transcriptionally. To study the hepatic miRNA content of postpartum dairy cows, including their overall abundance and differential expression, in mild NEB (MNEB) and severe NEB (SNEB), short read RNA sequencing was carried out. To identify putative targets of differentially expressed miRNAs among differentially expressed hepatic genes reported previously in dairy cows in SNEB computational target identification was employed.

Results: Our results indicate that the dairy cow liver expresses 53 miRNAs at a lower threshold of 10 reads per million. Of these, 10 miRNAs accounted for greater than 95\% of the miRNAome (miRNA content). Of the highly expressed miRNAs, miR-122 constitutes 75\% followed by miR-192 and miR-3596. Five out of thirteen let-7 miRNA family members are also among the highly expressed miRNAs. miR-143, down-regulated in SNEB, was found to have 4 putative up-regulated gene targets associated with SNEB including LRP2 (low density lipoprotein receptor-related protein 2), involved in lipid metabolism and up-regulated in SNEB.

Conclusions: This is the first liver miRNA-seq profiling study of moderate yielding dairy cows in the early postpartum period. Tissue specific miR-122 and liver enriched miR-192 are two of the most abundant miRNAs in the postpartum dairy cow liver. miR-143 is significantly down-regulated in SNEB and putative targets of miRNA-143 which are up-regulated in SNEB, include a gene involved in lipid metabolism.
\end{abstract}

Keywords: micro RNA, RNA-seq, Liver, Negative energy balance, Nutrition, Dairy cattle

\section{Background miRNAs}

miRNAs are among the most abundant and extensively studied class of small non-coding RNA. miRNAs are estimated to regulate the expression of up to $60 \%$ of mammalian protein coding genes [1] and are associated with many economically important traits in domestic livestock [2]. The biosynthesis of miRNA is comprised of multiple stages. The initial stage involves transcription of the miRNA gene to produce primary miRNAs, several hundred base-pairs in length, followed by the generation

\footnotetext{
* Correspondence: dermot.morris@teagasc.ie

'Animal and Bioscience Research Department, Animal \& Grassland Research and Innovation Centre, Teagasc, Mellows Campus, Athenry, Co, Galway, Ireland

Full list of author information is available at the end of the article
}

of 70 nucleotide-long hairpin shaped pre-miRNAs. Finally, Dicer-mediated processing results in the mature $\sim 22$ bp miRNA [3]. miRNA-mediated interference involves imperfect base-pairing of miRNAs, typically to the 3' UTR of the target mRNA. miRNAs have been reported to regulate gene expression in various biological pathways including those involved in metabolism and energy homeostasis [4]. In addition, miRNAs have been implicated in a wide variety of diseases $[5,6]$. The regulatory role of miRNAs in liver disease such as hepatitis, diet induced non-alcoholic fatty liver, alcoholic and nonalcoholic hepatocellular carcinoma and cirrhosis have been reported in humans and demonstrated in mouse liver studies [7-9]. In the case of beef cows, both liver specific and ubiquitously expressed miRNAs have been reported [10,11]. In another cow liver study, miRNAs 
were suggested as biomarkers for anabolic steroid abuse screening [12]. In addition, alterations in hepatic miRNAs in lambs have been associated with periconceptional changes in maternal nutrition [13].

\section{Negative energy balance}

The postpartum period is of critical importance for the general and reproductive health of dairy cows [14]. During the early postpartum period energy expenditure for maintenance and lactation exceeds energy intake from nutrition resulting in NEB [15]. NEB increases the risk of other metabolic disorders such as ketosis and fatty liver and animals are prone to infectious diseases, including mastitis, due to reduced immunity [16]. NEB has profound effects on the liver, which undergoes many physiological and biochemical changes to counteract the energy imbalance [15,17]. An energy balance model of early lactation dairy cows was developed previously $[18,19]$ resulting in two groups of cows with MNEB and SNEB. Alterations in gene expression in the liver associated with SNEB have been reported in two previous studies $[19,20]$.

In the first study, 416 genes were found to be differentially expressed due to SNEB using microarray-based expression profiling [19]. In the second study, using RNA-seq, 413 genes were shown to be differentially expressed [20] with 72 differentially expressed genes in common between the two studies. Both of these studies report the alteration of genes involved in lipid metabolism the main biological process altered during SNEB. The mechanisms, however, mediating these alterations in transciptome expression are yet to be fully understood. In a microarray-based and RT-qPCR validated study of liver miRNAs from this NEB model, five miRNAs were found to be up-regulated in SNEB [21]. Microarray expression profiling, however, is limited to the pre-defined probe sets on the array and only relative expression of miRNAs can be measured. On the other hand with RNA sequencing (RNA-seq) it is possible to measure the expression of all putative miRNAs in a sample [22]. As miRNA activity and function depend on abundance [23], accurate quantification of miRNA abundance is important $[24,25]$. miRNA sequencing is based on short read RNA-seq and involves generation and high-throughput sequencing of $50 \mathrm{bp}$ cDNA reads derived from the small RNA fraction of total RNA [26].

The objectives of this study were to (i) carry out an indepth global analysis of the hepatic miRNA content of postpartum dairy cows, including their overall abundance and differential expression, in MNEB and SNEB using RNA sequencing and (ii) to computationally identify putative targets of differentially expressed miRNAs among differentially expressed hepatic genes reported previously in dairy cows in SNEB.

\section{Results}

In total, more than 300 million reads were sequenced from eight cDNA libraries. Of these, more than 292 million reads passed quality control filters and just over 200 million reads aligned uniquely to Ensembl annotated genes in the UMD_3.1 assembly of the bovine genome. A summary of the data is provided in Table 1 and detailed statistics in Additional file 1: Table S1. 99\% of reads, which aligned uniquely to the genome, aligned to known miRNAs (Additional file 2: Table S2). The UMD_3.1 build of the bovine genome has 26,618 annotated genes and miRBase version 16 includes 792 Bos taurus miRNAs including both pre and mature miRNAs. There were 479 miRNAs for which at least one read was observed in each of the eight samples in our dataset. Out of these, 53 miRNAs were expressed above a mean threshold of 10 reads per million (RPM) across all eight samples.

The 10 most highly expressed miRNAs accounted for more than $95 \%$ of all miRNAs expressed (Figure 1 and Table 2). The liver miRNA expression profile was dominated by miR-122, which accounted for $75 \%$ of all highly expressed miRNAs. This was followed by miR-192 which accounted for $8 \%$ and the let 7 family member miR-3596 which accounted for over $7 \%$ of the most abundantly expressed miRNAs. The remaining seven most highly abundant miRNAs were four members of the let $7 \mathrm{fam}$ ily (let-7c, let-7i, let-7 $\mathrm{g}$ and let-7f-2) which accounted for $3 \%$ while miR-140 accounted for $\sim 1.5 \%$ and both miR-29a and miR-423 made up $\sim 0.5 \%$ each (Figure 1 ). The most highly expressed liver miRNAs are all evolutionary conserved and include five members of the 13member let-7 family (let-7c, let-7i, let-7 g, let-7f-2 and miR-3596). These miRNAs were located across nine different chromosomes with both let7-i and miR-3596 located on chromosome five. There was no evidence of clustering of highly expressed miRNAs in a particular genomic region. All are mature RNAs except for let-7f-2 a stem-loop miRNA. The relative abundances, sequences, genomic coordinates of highly expressed miRNAs are given in Table 2. One miRNA, miR-143 was differentially expressed between the SNEB and MNEB groups. miR-143 was 3.2-fold down-regulated in the SNEB group $(F D R<0.005)$ and was the $11^{\text {th }}$ most abundantly expressed (greater than 100,000 counts) miRNA The direction and magnitude of miR-143 regulation was confirmed (2.4-fold down-regulated) following RT-qPCR validation (Table 3 ).

In order to identify genes that may be affected by the down-regulation of miR-143 in SNEB, we computationally predicted miRNA targets among the 3'UTRs of a combined set of 757 hepatic genes that have been previously reported to be differentially expressed in the liver tissues of the same animals $[19,20]$. A total of 4 genes 
Table 1 Read statistics for SNEB and MNEB postpartum dairy cow liver miRNA-seq data

\begin{tabular}{lcccccc}
\hline Sample $^{*}$ & $\begin{array}{c}\text { Processed } \\
\text { reads }\end{array}$ & $\begin{array}{c}\text { Untrimmed } \\
\text { reads }\end{array}$ & $\begin{array}{c}\text { Reads after } \\
\text { QC }\end{array}$ & $\begin{array}{c}\text { Reads aligning to } \\
\text { UMD3.1.68† }\end{array}$ & $\begin{array}{c}\text { Reads aligning uniquely } \\
\text { to UMD3.1.68 }\end{array}$ & $\begin{array}{c}\text { Reads aligning } \\
\text { to genes }\end{array}$ \\
\hline 75 & $35,531,177$ & 319,143 & $33,034,345$ & $29,929,732$ & $22,008,536$ & $21,617,227$ \\
8S & $42,701,190$ & 212,634 & $42,060,747$ & $39,510,950$ & $28,788,096$ & $28,526,343$ \\
9S & $39,733,845$ & 276,697 & $35,308,457$ & $32,324,504$ & $24,940,747$ & $24,682,635$ \\
10S & $37,834,521$ & 326,905 & $34,658,341$ & $31,140,804$ & $22,754,746$ & $22,477,046$ \\
2M & $35,079,188$ & 272,113 & $32,996,280$ & $30,024,759$ & $23,042,362$ & $22,809,423$ \\
3M & $44,401,783$ & 289,778 & $43,107,430$ & $40,269,999$ & $30,931,375$ & $30,757,376$ \\
4M & $40,699,727$ & 280,820 & $32,868,631$ & $29,571,511$ & $23,373,573$ & $23,050,065$ \\
5M & $38,751,887$ & 198,345 & $38,079,095$ & $36,361,987$ & $34,268,099$ & $23,963,761$ \\
Sum & $314,733,318$ & $2,176,435$ & $292,113,326$ & $269,134,246$ & $210,107,534$ & $207,883,876$ \\
Average & $39,341,665$ & 272,054 & $36,514,166$ & $33,641,781$ & $26,263,442$ & $25,985,485$ \\
\hline
\end{tabular}

*S = SNEB; M=MNEB.

HUMD3.1.68 = Ensembl v68 annotation of the UMD3.1 assembly of the bovine genome.

reported to be up-regulated in SNEB were found to be putative targets of miR-143 (Table 4). The biological functions and intracellular location of these targets are given in Table 5.

\section{Discussion}

The postpartum increase in milk production in high yielding dairy cows is accompanied by increased nutritional and energetic demands. This results in 10-12 weeks of NEB in all high-yielding dairy cows [26]. Previous reports have shown that SNEB affects the expression of multiple genes in the liver, including genes involved in lipid and glucose metabolism and homeostasis $[19,20]$. Hepatic miRNAs have been reported to play a role in hepatic functions and disorders in human and mouse [27]. In addition miRNAs are reported to be associated with energy metabolism through their role in modulation of glucose and lipid homeostasis [28,29]. The miRNA profile of MNEB and SNEB dairy cow liver two weeks postpartum in this study shows some degree

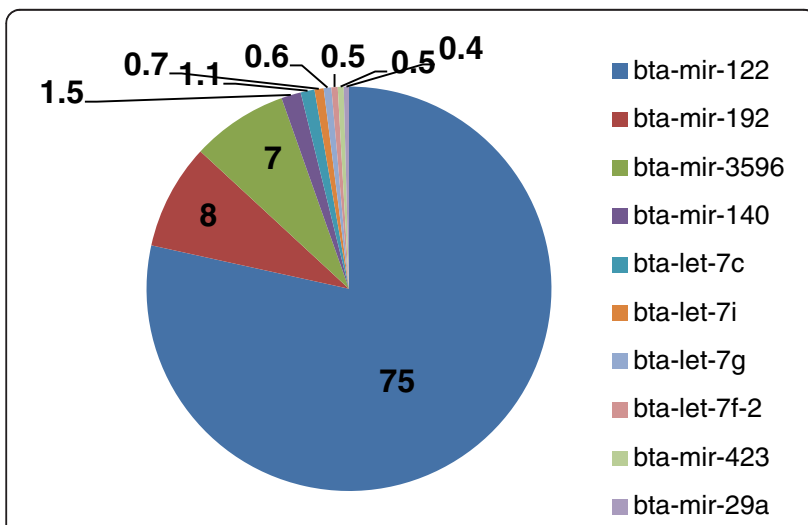

Figure 1 The 10 most abundant hepatic miRNAs in the postpartum dairy cow. of similarity with hepatic miRNA profiles of other animals including human, mouse, rat, and beef cows.

\section{Abundantly expressed miRNAs in postpartum dairy cow liver}

This is the first liver miRNA-seq profiling study of moderate yielding dairy cows in the first two weeks postpartum. The most dominant among the ten highly abundant miRNAs in our study, miR-122, is a liver-specific conserved miRNA. This dominance of expression by miR-122 is consistent with previous studies in dairy [10] and beef cows [11] where miR-122 was reported to be only expressed in liver, when compared with other tissues, and constituted more than $57 \%$ of all the miRNA reported in liver [11]. In addition, miR-122 has been reported to account for $70 \%$ of the total miRNAs in human liver [30]. Tissue specific roles of miR-122 are well established in human and miR-122 has been implicated in the hepatic disorders hepatocarcinogenesis and hepatocellular carcinoma [9,31,32]. Furthermore, the antagonism of miR-122 was reported to result in disruptions of cholesterol and lipid metabolism in mice [9]. The second most abundant miRNA in our study miR-192 has been associated with cellular responses to glucose stimulus [33] and was also reported to be one of the most highly expressed after miR-122 in human liver miRNA studies $[31,34]$ and in a mouse liver study [35]. miR-192 unlike miR-122 is not a liver specific miRNA and has also been reported to have important roles in human and bovine renal tissues and functions [36-38]. Five of the thirteen members of the let-7 family are also highly expressed in this study including let-7c, let-7i, let-7 g, miR-3596 and let-7-f. The let-7 family members have been associated with hepatic development and disorders as well as glucose and insulin metabolism [39]. Over-expression of let-7c in human liver was implicated in hepatocytes oxidant injury [40] while let-7 $\mathrm{g}$ was demonstrated to suppress HCC metastasis in a 
Table 2 Highly expressed miRNAs in postpartum dairy cows

\begin{tabular}{|c|c|c|c|c|}
\hline miRNAs & miR family & miRNA-seq counts & Sequence & Coordinates (UMD3.1.68)† \\
\hline miR-122 & miR-122 & 19364782 & UGGAGUGUGACAAUGGUGUUUG & chr24: 58095642-58095726 [+] \\
\hline miR-192 & miR-192 & 2083071 & CUGACCUAUGAAUUGACAGCCAG & chr29: 43731660-43731765 [+] \\
\hline miR-3596 & let 7 & 1902520 & AACCACACAACCUACUACCUCA & chr5: 117120188-117120270 [-] \\
\hline miR-140 & miR-140 & 385996 & UACCACAGGGUAGAACCACGGA & chr18: 37088137-37088230 [+] \\
\hline bta-let-7c & let 7 & 274368 & UGAGGUAGUAGGUUGUAUGGUU & chr1: 19930459-19930542 [-] \\
\hline bta-let-7i & let 7 & 179868 & UGAGGUAGUAGUUUGUGCUGUU & chr5: 51209081-51209164 [-] \\
\hline bta-let-7 g & let 7 & 150545 & UGAGGUAGUAGUUUGUACAGUU & chr22: 49189340-49189422 [+] \\
\hline bta-let-7f-2 & let 7 & 124091 & $\begin{array}{l}\text { UGUGGGAUGAGGUAGUAGAUUGUAUAGUUUUAGGGUCAUAC } \\
\text { CCCAUCUUGGAGAUAACUAUACAGUCUACUGUCUUUCCCACG }\end{array}$ & chrX: 96383532-96383614 [-] \\
\hline miR-423 & miR-423 & 116540 & AAGCUCGGUCUGAGGCCCCUCAGU & chr19: 21799484-21799577 [+] \\
\hline miR-29a & miR-29 & 115428 & CUAGCACCAUCUGAAAUCGGUUA & chr4: 95402319-95402382 [-] \\
\hline
\end{tabular}

mouse model [41]. miR-140, which is also among the highly expressed miRNAs in this study, has been reported to be abundantly expressed in human and mouse liver with implications in liver function and disorders [42-44].

\section{Differentially expressed miRNAs in postpartum dairy cow liver in SNEB}

Only one miRNA, miR-143 was found to be differentially expressed in this study using miRNA-seq and subsequently validated by RT-qPCR. This may have been due in part to the fact that most of the sequence reads in this study came from a small number of miRNAs possibly limiting the power of RNA-seq to accurately estimate the abundance of the more lowly expressed miRNAs. Less abundant miRNAs would not be affected to the same extent in a microarray based approach which has probes corresponding to known miRNAs. In a previous microarray-based study of the same animals, ten miRNAs were found to be differentially expressed; five of which were validated using RT-qPCR [21]. In this study, one additional miRNA bta-miR-1247, would have been declared differentially expressed were it not excluded from the analysis due to having read counts below the lower threshold criterion of 10 reads per million. In addition, in this study a cut-off of 18 nts in length was used in the analysis, whereas in the microarray study, miR-1281 which was found to be differentially expressed is $17 \mathrm{nts}$ in length.

miR-143, a highly expressed miRNA in this study, is down-regulated in SNEB. miR-143 is not liver-specific,

Table 3 Differentially expressed miRNA in SNEB postpartum dairy cow liver validated using RT-qPCR

\begin{tabular}{cccc}
\hline Ensemble gene & miRBase ID & FC & FDR \\
\hline ENSBTAG00000030114 & bta-mir-143 & -2.40 & 0.029 \\
\hline
\end{tabular}

Differential expression analysis was carried out with PROC t-test (SAS) after normalization of Ct-values to reference gene RNU6B. however its tissue-enriched expression has been reported in human [45] chicken [46], rat [43] and mouse $[47,48]$ liver. In the case of human, miR-143 has been implicated in hepatocellular carcinoma. In the rat study, miR-143 was demonstrated to regulate activation and proliferation of myofibroblastic hepatic stellate cells (HSC) while in the mouse study miR-143 was shown to regulate glucose metabolism in vitro, and was associated with hepatic insulin regulation. In addition, miR-143 has been found to be ubiquitously expressed in bovine tissues including liver [10] and has also been associated with bovine intramuscular fat proliferation and differentiation [49] and high back fat deposition in crossbred beef cattle [50].

\section{Some important predicted gene targets of miRNA} miR-143

Of the 4 putative targets of miR-143 which have been reported previously to be up-regulated in SNEB, LRP2 is involved in lipid metabolism and is of particular interest because the metabolism of lipids is altered during SNEB [51,52]. LRP2 is implicated in lipid metabolism through its role as a receptor for sterols, steroid hormones bound to carrier proteins [53] like lipoproteins [54] and apolipoprotein $M$ of liver [55-57]. A study of miRNA based modulation of obesity also reported LRP2 as a putative target of miR-130a, with roles in lipid metabolism [58].

Table 4 Up-regulated putative hepatic gene targets of miR-143 in postpartum dairy cows in SNEB ${ }^{\dagger}$

\begin{tabular}{ccc}
\hline Human gene name & Fold change & FDR \\
\hline CHRM1 & 4.3 & 0.004222 \\
LRP2 & 3.28 & 0.015161 \\
ARHGEF40 & 2.85 & $1.34 \mathrm{E}-06$ \\
C6orf145 & 2.1 & $1.02 \mathrm{E}-06$ \\
\hline
\end{tabular}

${ }^{\dagger}$ From Mc Carthy et al., [19]; McCabe et al., [20]. 
Table 5 Functional categories of up-regulated putative target hepatic genes of miR-143

\begin{tabular}{lllll}
\hline ID & Symbol & Entrez gene name & Location & Type(s) \\
\hline CHRM1 & CHRM1 & cholinergic receptor, muscarinic 1 & Plasma Membrane & G-protein coupled receptor \\
LRP2 & LRP2 & low density lipoprotein receptor-related protein 2 & Plasma Membrane & Transporter \\
ARHGEF40 & ARHGEF40 & Rho guanine nucleotide exchange factor (GEF) 40 & unknown & Enzyme \\
C6orf145 & PXDC1 & PX domain containing 1 & unknown & Signalling protein \\
\hline
\end{tabular}

${ }^{\dagger}$ Target genes are those predicted using both TargetScan and miRanda.

\section{Conclusions}

From a global examination of miRNA expression in the liver of postpartum dairy cattle ten highly expressed miRNAs dominate. Tissue specific miR-122 and liver enriched miR-192 are two of the most abundant miRNAs in the postpartum dairy cow liver. miR-143 is significantly down-regulated in SNEB and putative targets of miRNA-143 up-regulated in SNEB, include LRP2 a good candidate as a potential mediator of the metabolic effects of NEB.

\section{Methods}

NEB model

A NEB dairy cow model developed previously was used. In this model differential feeding and milking regimes were used to produce two groups of Holstein Friesian cows; MNEB and SNEB $[18,19]$. Briefly, MNEB cows were fed ad libitum grass silage with $8 \mathrm{~kg} /$ day of a $21 \%$ crude protein dairy concentrate and milked once daily. SNEB cows were fed $25 \mathrm{~kg} /$ day silage with $4 \mathrm{~kg} /$ day concentrate and milked thrice daily.

\section{Liver tissue collection for miRNA analysis}

All procedures were carried out under license in accordance with the European Community Directive, 86-609-EC. Cows were slaughtered approximately 14 days postpartum (MNEB; 13.6 \pm 0.75 , range 11-15; SNEB $14.3 \pm$ 0.56 , range 13-16) and the entire liver was removed within 15 to $30 \mathrm{~min}$ [19]. Samples weighing approximately $1 \mathrm{~g}$ were dissected, rinsed in RNAase-free phosphate buffer, snap-frozen in liquid nitrogen and stored at $-80^{\circ} \mathrm{C}$. Liver tissue samples from 4 animals from each group were used for miRNA library preparation.

\section{RNA extraction and library preparation}

Total RNA enriched for small RNA was extracted from $1 \mathrm{mg}$ of frozen tissue from each of the eight samples using the mirVana ${ }^{\text {tw }}$ miRNA Isolation Kit (Life Technologies, Carlsbad, CA, USA) according to the manufacturer's protocol. The RNA extract was stored at $-80^{\circ} \mathrm{C}$. An Agilent RNA 6000 Nano Kit and the 2100 Bioanalyzer was used to measure total RNA integrity (Agilent Technologies, Colorado Springs, CO, USA) and the Agilent Small RNA Kit (Agilent Technologies) was used for miRNA quantification. Small RNA libraries were constructed at BGI (Shenzhen, China) under contract and sequenced on an Illumina HiSeq2000 platform.

\section{Data analysis pipeline}

FASTQC v0.10.0 (http://www.bioinformatics.babraham.ac. $\mathrm{uk} /$ projects/fastqc/) was used to carry out preliminary quality control of the 8 FASTQ files. The 3 ' adaptor sequences were trimmed with Cutadapt v1.1 (https://code. google.com/p/cutadapt). After trimming, reads shorter than 18 nucleotides were discarded. The FASTQ quality filter v0.0.13 (http://hannonlab.cshl.edu/fastx_toolkit/) was applied to trim low quality bases from reads. Phred scores were calculated and reads where at least $50 \%$ of the bases had a Phred score of less than 20 were discarded [59]. The filtered reads were further trimmed at their ends to remove low quality bases (Phred score $<20$ ). Reads were then aligned to the bovine genome (UMD3.1) using Novoalign version 2.07.11 (http://www.novocraft.com) using the "-m" miRNA mode. Only uniquely aligned reads were retained. HTSeq version 0.5.3p3 (http://www-huber.embl.de/users/ anders/HTSeq/doc/overview.html) was used to annotate uniquely aligned reads using Ensembl (v68) bovine gene and miRNA annotation.

\section{Differential expression analysis}

As differential expression analysis of miRNAseq data is sensitive to the normalisation method a number of alternative methods were used [60]. Differential expression was assessed following normalisation of count data using either the trimmed mean of M-values (TMM), the upper quartile-normalisation method or no normalisation using the Bioconductor package EdgeR (v2.4.6). EdgeR which uses a negative binomial model to account for both biological and technical variability was used to identify differentially expressed miRNAs between the two groups using moderated tag wise dispersions. A Benjamini and Hochberg [61] corrected P value cut-off of $<0.05$ was applied to correct for multiple testing. Only miRNAs expressed above a threshold of 10 reads per million were considered for the differential expression analysis as miRNAs expressed below this threshold are unlikely to be functional.

\section{RT-qPCR validation of differentially expressed miRNAs}

RT-qPCR was used for technical validation of differentially expressed miRNA using TaqMan miRNA assay 
(Applied Biosystems, Dublin, Ireland). Gene-specific reverse transcription was performed on $10 \mathrm{ng}$ of purified total RNA using the TaqMan MicroRNA Reverse Transcription kit according to manufacturer's instructions (Applied Biosystems, Dublin, Ireland). RT-qPCR reactions were performed using $1 \mu \mathrm{l}$ of cDNA $(10 \mathrm{ng} / \mu \mathrm{l})$ in $9 \mu \mathrm{l}$ of Taqman universal master mix containing TaqMan PCR primers and probes on a BioRad CFX96 real time PCR system (Bio-Rad, United Kingdom) using the following cycling parameters: $95^{\circ} \mathrm{C}$ for 10 min followed by 40 cycles at $95^{\circ} \mathrm{C}$ for $15 \mathrm{~s}$ and $60^{\circ} \mathrm{C}$ for $1 \mathrm{~min}$. A total of four biological replicates from each of the MNEB and SNEB treatment groups were used for RT-qPCR validation. From prior experience with microarray hepatic miRNA expression validation and using the same liver tissue samples from the same animals, RNU6B was chosen as the most stable internal reference miRNA [21]. miRNA expression levels were recorded as $\mathrm{Ct}$ values, i.e., the number of PCR cycles at which the fluorescence signal is detected above the threshold value. The software package BioRad CFX manager was used for correction of the $\mathrm{Ct}$ values and normalization to RNU6B using the $2^{-\Delta \Delta C t}$ method [62]. Corrected Ct values were used to calculate differential expression using the PROC $t$-test (SAS) [63]. A P $<0.05$ was deemed to be significant.

\section{MiRNA target predictions}

Both TargetScan Release 6.2 (www.targetscan.org) $[1,64,65]$ and miRanda v4.0 (www.microrna.org) [66] were used to predict common targets of differentially expressed miRNAs among the two datasets of up-regulated hepatic genes previously reported for liver tissues from the same cows $[19,20]$.

\section{Availability of supporting data}

The data sets supporting the results of this article are available in Gene Expression Omnibus (GEO) repository GSE55882 http://www.ncbi.nlm.nih.gov/geo/query/acc.cgi? acc $=$ GSE55882.

\section{Additional files}

Additional file 1: Table S1. Detailed summary of RNA-seq data for postpartum dairy cow liver

Additional file 2: Table S2. Percentage distribution of RNA biotypes.

\section{Competing interests}

The authors declare that they have no competing interests.

\section{Authors' contributions}

DM, CS conceived and designed the experiments. AF, PO performed the experiments. AF, CS, DL, DM analysed the data. AF, CS, DM, DL drafted the manuscript. All authors read and approved the final manuscript.
Authors' information

Cathal Seoighe and Dermot G Morris are joint senior authors.

\section{Acknowledgements}

The authors would like to acknowledge a Teagasc Walsh Fellowship and funding for $\mathrm{AF}$

\section{Author details}

${ }^{1}$ Animal and Bioscience Research Department, Animal \& Grassland Research and Innovation Centre, Teagasc, Mellows Campus, Athenry, Co, Galway, Ireland. ${ }^{2}$ School of Mathematics, Statistics and Applied Mathematics National University of Ireland Galway, Galway, Ireland. ${ }^{3}$ Animal and Bioscience Research Department, Animal \& Grassland Research and Innovation Centre, Grange, Dunsany, Co, Meath, Ireland.

Received: 17 December 2013 Accepted: 8 April 2014 Published: 12 April 2014

\section{References}

1. Friedman RC, Farh KK, Burge CB, Bartel DP: Most mammalian mRNAs are conserved targets of microRNAs. Genome Res 2009, 19(1):92-105.

2. Fatima A, Morris DG: Review: microRNAs in domestic livestock. Physiol Genomics 2013, 45(16):685-696.

3. Lee $Y$, Jeon K, Lee J-T, Kim S, Kim VN: MicroRNA maturation: stepwise processing and subcellular localization. EMBO J 2002, 21(17):4663-4670.

4. Dumortier O, Hinault C, Van Obberghen E: MicroRNAs and Metabolism Crosstalk in Energy Homeostasis. Cell Metab 2013, 18(3):312-324.

5. Ming M, Zhao X, Zhao Z-y, Liu B, Bao J-k: MicroRNA regulation of programmed cell death pathways in cancer. Curr Chem Biol 2012, 6(1):53-59.

6. Pandey AK, Agarwal P, Kaur K, Datta M: MicroRNAs in diabetes: tiny players in big disease. Cell Physiol Biochem 2009, 23(4-6):221-232.

7. Alisi A, Da Sacco L, Bruscalupi G, Piemonte F, Panera N, De Vito R, Leoni S, Bottazzo GF, Masotti A, Nobili V: Mirnome analysis reveals novel molecular determinants in the pathogenesis of diet-induced nonalcoholic fatty liver disease. Lab Invest 2010, 91(2):283-293.

8. Bala S, Marcos M, Szabo G: Emerging role of microRNAs in liver diseases. World J Gastroenterol 2009, 15(45):5633-5640.

9. Tsai W-C, Hsu S-D, Hsu C-S, Lai T-C, Chen S-J, Shen R, Huang Y, Chen H-C, Lee C-H, Tsai T-F: MicroRNA-122 plays a critical role in liver homeostasis and hepatocarcinogenesis. J Clin Invest 2012, 122(8):2884-2897.

10. Gu Z, Eleswarapu S, Jiang H: Identification and characterization of microRNAs from the bovine adipose tissue and mammary gland. FEBS Lett 2007, 581(5):981-988.

11. Jin W, Grant JR, Stothard P, Moore SS, Guan LL: Characterization of bovine miRNAs by sequencing and bioinformatics analysis. BMC Mol Biol 2009, 10(1):90

12. Becker C, Riedmaier I, Reiter M, Tichopad A, Pfaffl MW, Meyer HHD: Changes in the miRNA profile under the influence of anabolic steroids in bovine liver. Analyst 2011, 136(6):1204-1209.

13. Nicholas LM, Rattanatray L, MacLaughlin SM, Ozanne SE, Kleemann DO, Walker SK, Morrison JL, Zhang S, Muhlhäusler BS, Martin-Gronert MS: Differential effects of maternal obesity and weight loss in the periconceptional period on the epigenetic regulation of hepatic insulin-signaling pathways in the offspring. FASEB J 2013, 27(9):3786-3796.

14. Sheldon IM: The postpartum uterus. Vet Clin North Am Food Anim Pract 2004, 20(3):569-591.

15. Wathes DC, Fenwick MA, Llewellyn S, Cheng Z, Fitzpatrick R, McCarthy SD, Morris DG, Patton J, Murphy JJ: Influence of energy balance on gene expression in the liver and reproductive tract of lactating cows and consequent effects on fertility. In XXV Jubilee World Buiatrics Congress Hungarian Association for Buiatrics 2008. Budapest, Hungary; 2008:158-171. http://www.blaguss-congress.hu/ xxvwbc2008/pdf/programmebook.pdf.

16. Liu GW, Zhang ZG, Wang JG, Wang Z, Xu C, Zhu XL: Insulin receptor gene expression in normal and diseased bovine liver. J Comp Pathol 2010, 143(4):258-261.

17. Thomas C, Leach K, Logue D, Ferris C, Phipps R: Management options to reduce load. Cattle Pract 1999, 7:121-122

18. Patton J, Kenny D, Mee J, O'Mara F, Wathes D, Cook M, Murphy J: Effect of milking frequency and diet on milk production, energy balance, and reproduction in dairy cows. J Dairy Sci 2006, 89:1478-1487. 
19. McCarthy SD, Waters SM, Kenny DA, Diskin MG, Fitzpatrick R, Patton J, Wathes DC, Morris DG: Negative energy balance and hepatic gene expression patterns in high-yielding dairy cows during the early postpartum period: a global approach. Physiol Genomics 2010, 42(3):188-199.

20. McCabe M, Waters S, Morris D, Kenny D, Lynn D, Creevey C: RNA-seq analysis of differential gene expression in liver from lactating dairy cows divergent in negative energy balance. BMC Genomics 2012, 13(1):193

21. Fatima A, Waters S, O'Boyle P, Seoighe C, Morris D: Alterations in hepatic miRNA expression during negative energy balance in postpartum dairy cattle. BMC Genomics 2014, 15:28.

22. Gunaratne PH, Coarfa C, Soibam B, Tandon A: miRNA data analysis: next-gen sequencing. Methods Mol Biol 2012, 822:273-288.

23. Ebert MS, Sharp PA: Roles for microRNAs in conferring robustness to biological processes. Cell 2012, 149(3):515-524.

24. Sarasin-Filipowicz M, Krol J, Markiewicz I, Heim MH, Filipowicz W: Decreased levels of microRNA miR-122 in individuals with hepatitis $C$ responding poorly to interferon therapy. Nat Med 2009, 15(1):31-33

25. Brown BD, Gentner B, Cantore A, Colleoni S, Amendola M, Zingale A, Baccarini A, Lazzari G, Galli C, Naldini L: Endogenous microRNA can be broadly exploited to regulate transgene expression according to tissue, lineage and differentiation state. Nat Biotechnol 2007, 25(12):1457-1467.

26. Garber M, Grabherr MG, Guttman M, Trapnell C: Computational methods for transcriptome annotation and quantification using RNA-seq. Nat Methods 2011, 8(6):469-477.

27. Kaur K, Pandey AK, Srivastava S, Srivastava AK, Datta M: Comprehensive miRNome and in silico analyses identify the Wnt signaling pathway to be altered in the diabetic liver. Mol Biosyst 2011, 7(12):3234-3244.

28. Chen B, Li H, Zeng X, Yang P, Liu X, Zhao X, Liang S: Roles of microRNA on cancer cell metabolism. J Transl Med 2012, 10:228.

29. Rottiers $V$, Naarr AM: MicroRNAs in metabolism and metabolic disorders. Nat Rev Mol Cell Biol 2012, 13(4):239-250.

30. Jopling C: Liver-specific microRNA-122: Biogenesis and function. RNA Biol 2012, 9(2):137-142

31. Hou J, Lin L, Zhou W, Wang Z, Ding G, Dong Q, Qin L, Wu X, Zheng $Y$, Yang $Y$ : Identification of miRNomes in human liver and hepatocellular carcinoma reveals miR-199a/b-3p as therapeutic target for hepatocellular carcinoma. Cancer Cell 2011, 19(2):232-243.

32. Zeng C, Wang R, Li D, Lin XJ, Wei QK, Yuan Y, Wang Q, Chen W, Zhuang SM: A novel GSK 3 beta C/EBP alpha miR-122 insulin like growth factor 1 receptor regulatory circuitry in human hepatocellular carcinoma. Hepatology 2010, 52(5):1702-1712.

33. Pogribny IP, Starlard-Davenport A, Tryndyak VP, Han T, Ross SA, Rusyn I, Beland FA: Difference in expression of hepatic microRNAs miR-29c, miR-34a, miR-155, and miR-200b is associated with strain-specific susceptibility to dietary nonalcoholic steatohepatitis in mice. Lab Invest 2010, 90(10):1437-1446.

34. Li N, You X, Chen T, Mackowiak SD, Friedlander MR, Weigt M, Du H, Gogol-Doring A, Chang Z, Dieterich C: Global profiling of miRNAs and the hairpin precursors: insights into miRNA processing and novel miRNA discovery. Nucleic Acids Res 2013, 41(6):3619-3634.

35. Wang K, Zhang S, Marzolf B, Troisch P, Brightman A, Hu Z, Hood LE, Galas DJ: Circulating microRNAs, potential biomarkers for drug-induced liver injury. Proc Natl Acad Sci 2009, 106(11):4402-4407.

36. Chung ACK, Huang XR, Meng X, Lan HY: miR-192 mediates TGF-beta/Smad3-driven renal fibrosis. J Am Soc Nephrol 2010, 21(8):1317-1325

37. Coutinho LL, Matukumalli LK, Sonstegard TS, Van Tassell CP, Gasbarre LC, Capuco AV, Smith TPL: Discovery and profiling of bovine microRNAs from immune-related and embryonic tissues. Physiol Genomics 2007, 29(1):35-43.

38. Tesfaye D, Worku D, Rings F, Phatsara C, Tholen E, Schellander K, Hoelker M: Identification and expression profiling of microRNAs during bovine oocyte maturation using heterologous approach. Mol Reprod Dev 2009, 76(7):665-677.

39. Ma J, Jiang $Z$, He $S$, Liu $Y$, Chen L, Long $K$, Jin $L$, Jiang $A$, Zhu L, Wang J, Li M, Li X: Intrinsic Features in MicroRNA Transcriptomes Link Porcine Visceral Rather than Subcutaneous Adipose Tissues to Metabolic Risk PLoS One 2013, 8(11):e80041.
40. Hou W, Tian Q, Steuerwald NM, Schrum LW, Bonkovsky HL: The let-7 microRNA enhances heme oxygenase-1 by suppressing Bach1 and attenuates oxidant injury in human hepatocytes. Biochim Biophys Acta (BBA)-Gene Regulatory Mechanisms 2012, 1819(11):1113-1122.

41. Ji J, Zhao L, Budhu A, Forgues M, Jia H-L, Qin L-X, Ye Q-H, Yu J, Shi X, Tang Z-Y: Let-7g targets collagen type I alpha2 and inhibits cell migration in hepatocellular carcinoma. J Hepatol 2010, 52(5):690-697.

42. Ferland-McCollough D, Ozanne S, Siddle K, Willis A, Bushell M: The involvement of microRNAs in Type2 diabetes. Biochem Soc Trans 2010, 38(6):1565-1570

43. Fowell AJ, Sanchez-Elsner T, Benyon RC, Rosenberg WM, Collins JE: Differential expression of microRNAs during hepatic stellate cell activation and their role in the regulation of hepatic stellate cell proliferation and apoptosis. Gut 2010, 59(Suppl 2):A8.

44. Zheng L, LV G, Sheng J, Yang Y: Effect of miRNA-10b in regulating cellular steatosis level by targeting PPAR-a expression, a novel mechanism for the pathogenesis of NAFLD. J Gastroenterol Hepatol 2010, 25(1):156-163.

45. Zhang X, Liu S, Hu T, Liu S, He Y, Sun S: Up-regulated microRNA 143 transcribed by nuclear factor kappa $B$ enhances hepatocarcinoma metastasis by repressing fibronectin expression. Hepatology 2009, 50(2):490-499.

46. Trakooljul N, Hicks JA, Liu H: Identification of target genes and pathways associated with chicken microRNA miR-143. Anim Genet 2010, 41(4):357-364.

47. Jordan SD, Krager M, Willmes DM, Redemann N, Wunderlich FT, Branneke HS, Merkwirth C, Kashkar H, Olkkonen VM, Battger T: Obesity-induced overexpression of miRNA-143 inhibits insulin-stimulated AKT activation and impairs glucose metabolism. Nat Cell Biol 2011, 13(4):434-446.

48. Ono K: MicroRNA links obesity and impaired glucose metabolism Cell Res 2011, 21(6):864-866.

49. Li H, Zhang Z, Zhou X, Wang Z, Wang G, Han Z: Effects of microRNA-143 in the differentiation and proliferation of bovine intramuscular preadipocytes. Mol Biol Rep 2011, 38(7):4273-4280.

50. Jin W, Dodson MV, Moore SS, Basarab JA: Characterization of microRNA expression in bovine adipose tissues: a potential regulatory mechanism of subcutaneous adipose tissue development. BMC Mol Biol 2010, $11(1): 29$

51. Harfoot CG, Hazlewood GP: Lipid metabolism in the rumen. In The Rumen Microbial Ecosystem. Netherlands: Springer; 1997:382-426.

52. Grummer RR: Etiology of lipid-related metabolic disorders in periparturient dairy cows. J Dairy Sci 1993, 76(12):3882-3896.

53. Willnow TE, Hammes A, Eaton S: Lipoproteins and their receptors in embryonic development: more than cholesterol clearance. Development 2007, 134(18):3239-3249.

54. May P, Woldt E, Matz RL, Boucher P: The LDL receptor-related protein (LRP) family: an old family of proteins with new physiological functions. Ann Med 2007, 39(3):219-228.

55. Dahlback B, Nielsen LB: Apolipoprotein M-a novel player in high-density lipoprotein metabolism and atherosclerosis. Curr Opin Lipidol 2006, 17(3):291-295

56. Dahlback B, Nielsen LB: Apolipoprotein M affecting lipid metabolism or just catching a ride with lipoproteins in the circulation? Cell Mol Life Sci 2009, 66(4):559-564.

57. Faber K, Hvidberg V, Moestrup SK, Dahlback B, Nielsen LB: Megalin is a receptor for apolipoprotein $M$, and kidney-specific megalin-deficiency confers urinary excretion of apolipoprotein M. Mol Endocrinol 2006, 20(1):212-218

58. Perri R, Nares S, Zhang S, Barros SP, Offenbacher S: MicroRNA modulation in obesity and periodontitis. J Dent Res 2012, 91(1):33-38.

59. Cock P, Fields C, Goto N, Heuer M, Rice P: The Sanger FASTQ file format for sequences with quality scores, and the Solexa/Illumina FASTQ variants. Nucleic Acids Res 2010, 38:1767-1771.

60. Garmire LX, Subramaniam S: Evaluation of normalization methods in mammalian microRNA-Seq data. RNA 2012, 18(6):1279-1288.

61. Benjamini $Y$, Hochberg $Y$ : Controlling the false discovery rate: a practical and powerful approach to multiple testing. J R Soc Stat Soc Ser B (Methodological) 1995, 57(1):289-300.

62. Schmittgen T, Livak K: Analyzing real-time PCR data by the comparative CT method. Nat Protoc 2008, 3(6):1101-1108

63. Yuan J, Reed A, Chen F, Stewart C: Statistical analysis of real-time PCR data. BMC Bioinformatics 2006, 7(1):85 
64. Grimson A, Farh KK-H, Johnston WK, Garrett-Engele P, Lim LP, Bartel DP: MicroRNA Targeting Specificity in Mammals: determinants beyond Seed Pairing. Mol Cell 2007, 27(1):91-105.

65. Lewis BP, Burge CB, Bartel DP: Conserved seed pairing, often flanked by adenosines, indicates that thousands of human genes are microRNA targets. Cell 2005, 120(1):15-20.

66. Betel D, Wilson M, Gabow A, Marks DS, Sander C: The microRNA.org resource: targets and expression. Nucleic Acids Res 2008, 36(suppl 1):D149-D153.

doi:10.1186/1471-2164-15-279

Cite this article as: Fatima et al:: The miRNAome of the postpartum

dairy cow liver in negative energy balance. BMC Genomics 2014 15:279.

Submit your next manuscript to BioMed Central and take full advantage of:

- Convenient online submission

- Thorough peer review

- No space constraints or color figure charges

- Immediate publication on acceptance

- Inclusion in PubMed, CAS, Scopus and Google Scholar

- Research which is freely available for redistribution 